\section{(6) OPEN ACCESS}

\title{
Association of flavoured cigar regulations with wholesale tobacco volumes in Canada: an interrupted time series analysis
}

\author{
Michael 0 Chaiton, ${ }^{\oplus 1,2}$ Robert Schwartz, ${ }^{1,2}$ Gabrielle Tremblay, ${ }^{3}$ Robert Nugent ${ }^{3}$
}

\begin{abstract}
- Additional material is published online only. To view please visit the journal online (http://dx.doi.org/10.1136/ tobaccocontrol-2018-054255).

1Ontario Tobacco Research Unit, University of Toronto, Toronto, Ontario, Canada

${ }^{2}$ Dalla Lana School of Public Health, University of Toronto, Toronto, Ontario, Canada ${ }^{3}$ Tobacco Control Directorate, Health Canada, Ottawa, Ontario, Canada
\end{abstract}

\section{Correspondence to} Michael O Chaiton, Ontario Tobacco Research Unit, University of Toronto, Toronto, ON M5T 3M7, Canada; michael.chaiton@utoronto.ca

Received 12 January 2018 Revised 20 July 2018 Accepted 30 July 2018 Published Online First 22 August 2018

\begin{abstract}
Introduction This study examines the association of Federal Canadian regulations passed in 2009 addressing flavours (excluding menthol) in small cigars with changes in cigar sales.
\end{abstract}

Methods Quarterly wholesale unit data as reported to Health Canada from 2001 through 2016 were analysed using interrupted time series analysis. Changes in sales of cigars with and without flavour descriptors were estimated. Analyses were seasonally adjusted. Changes in the flavour types were assessed over time.

Results The Federal flavour regulations were associated with a reduction in the sales of flavoured cigars by 59 million units $(95 \% \mathrm{Cl}-86.0$ to -32.4$)$. Increases in sales of cigars with descriptors other than flavours (eg, colour or other ambiguous terms) were observed (9.6 million increase $(95 \% \mathrm{Cl}-1.3$ to 20.5$)$, but the overall level (decline of 49.6 million units $(95 \% \mathrm{Cl}-73.5$ to -25.8 ) and trend of sales of cigars ( 6.9 million units per quarter $(95 \% \mathrm{Cl}-8.1$ to -5.7$))$ declined following the ban. Sensitivity analysis showed that there was no substantial difference in effect over time comparing Ontario and British Columbia, suggesting that other provincial tobacco control legislation was not associated with the changes in levels. Analyses suggested that the level change was sensitive to the specification of the date.

Conclusion This study demonstrates that flavour regulations have the potential to substantially impact tobacco sales. However, exemptions for certain flavours and product types may have reduced the effectiveness of the ban, indicating the need for comprehensive, welldesigned regulations.

\section{INTRODUCTION}

Many governments around the world have taken an interest in tobacco flavour regulation. For instance, the Food and Drug Administration in the USA was given the authority in 2010 to regulate flavours in tobacco, has banned flavours in cigarettes, and is considering banning or regulating flavours in other tobacco products. ${ }^{1}$ In addition, the European Union (EU) has announced the regulation of flavours in a 2014 Tobacco Products Directive. ${ }^{1}$ There are several underlying reasons for regulating flavours in tobacco products. Smokers have been found to perceive flavoured tobacco products as healthier, more appealing and less harsh than unflavoured products. ${ }^{1}$ Smokers who used flavoured tobacco products were also less likely to report intentions to quit smoking. ${ }^{1}$ Regulators in Canada, the USA, the EU and elsewhere are concerned that some flavours, particularly candy-flavoured and fruit-flavoured cigarettes, are appealing, especially to youth. Tobacco industry documents suggest that flavoured products are perceived to have better aromas and after taste, and spark interest and curiosity among users about trying the products. ${ }^{2}$

Previous bans in New York City have been evaluated by Farley and Johns ${ }^{3}$ and Rogers et $a l{ }^{4}{ }^{4}$ who found divergent results. Farley and Johns ${ }^{3}$ found that sales of flavoured cigars declined $86 \%$ with the ban, while non-flavoured sales increased for cigars $(5 \% ; \mathrm{p}=0.003)$. On the other hand, Rogers et $a l^{4}$ attributed a much smaller decline in sales of flavoured cigars of $22 \%$ and found no substitution of non-flavoured cigars after adjusting for nationwide trends. ${ }^{4}$ These studies differ by the use of dollar sales (Farley and Johns) ${ }^{3}$ compared with unit sales (Rogers et al), ${ }^{4}$ the choice of date of implementation, and differences in the source of scanner data for retail sales.

On 8 October 2009, the Government of Canada enacted new regulations on the sale of flavoured tobacco, banning flavour additives (except menthol) in cigarettes and all cigars under $1.4 \mathrm{~g}$ (or in any cigar that had a filter or non-spiral wrap). ${ }^{5}$ These regulations were aimed at protecting young persons from inducements to use tobacco, as emerging research had shown that over one-third of youth smokers were using flavoured cigars and cigarillos. ${ }^{6}$ The prevalence of flavoured tobacco product use in the last 30 days among Canadian students in grades 9 through 12 continues to be high, at $10 \%$ in 2013. ${ }^{7}$ This is consistent with the rates of use among US students: in 2014, 12\% of US middle and high school students used flavoured tobacco products in the past 30 days, ${ }^{8}$ while $19 \%$ of US young adults reported use of flavoured tobacco products in the past 30 days. $^{9}$

The Canadian government requires that all tobacco manufacturers, including importers, report wholesale sales (units and value) by specific brands, each quarter, for smokeless tobacco and cigar products. These data have only recently been made available, on a restricted basis, to researchers outside of Health Canada. To investigate the association of the flavour regulations on cigar sales, this study uses the wholesale sales volumes to examine trends in sales of flavoured cigar products during the 2004-2016 period, using equal periods of 6 years before and 6 years after enactment. This analysis also examines trends in flavour descriptors over this time. Research on the impact of flavouring regulations is critical to maximising 
the public health impacts of this relatively new tobacco control intervention.

\section{METHODS}

\section{Study design and setting}

This study uses an interrupted time series design to assess the 2009 regulations using aggregate quarterly sales. Interrupted time series is a useful method to examine non-randomised interventions ${ }^{10}$ and have been used previously to evaluate many other policy interventions, including the impact of sales taxes on tobacco in California. ${ }^{11}$ The main analysis compares the level and trends of sales of cigars in the 6 years prior to the intervention to the 6 years after the intervention in each of the 10 provinces. The intervention is the regulation that restricts the sale of flavoured cigars of less than $1.4 \mathrm{~g}$ or in any cigar that mimicked cigarettes with filter or non-spiral wrap. Menthol was also exempted. The regulations were published on 8 October 2009. The 2004-2016 period allows for an equal period before and after the first Federal regulation and does not address additional regulations that extended the flavour restrictions to other types of cigars effective 15 December 2015.

The Federal Government regulations were enacted at the same time as the major provincial tobacco legislation in Canada's largest province of Ontario. While Ontario's measures enacted on 1 January 2010 were substantively similar to the Federal Government regulations at the time and overlapped in terms of implementation, the Ontario legislation also included new restrictions on smoking in public places, restrictions on smoking in cars with children, promotion display bans at retail and additional restrictions aimed at limiting sale to youth under 19. In order to attempt to control for the potential confounding effect of other tobacco regulations in Ontario, Canada's largest province, trends in Ontario in sales of cigars are compared with trends in British Columbia. British Columbia (with a 2016 population of 4.6 million) is the jurisdiction with the lowest smoking prevalence in Canada but shares a number of similar demographic characteristics with Ontario (with a 2016 population of 14.0 million), such as high immigrant population and a robust economy; however, British Columbia did not have substantial tobacco control legislation in this period. Consequently, the 2009 measures are hypothesised to be consistent in both provinces if due to the Federal regulations, rather than other regulations implemented in Ontario at the time.

\section{Data source}

This analysis uses wholesale sales data as reported to Health Canada. Cigar sales are reported on a quarterly basis by brand and province. Under section 13 of the Government of Canada's Tobacco Reporting Regulations (TRR) (Tobacco Reporting Regulations, SOR/2000-273), manufacturers are required to report for each brand and unique brand descriptor the number of units or volume sold, package sizes, as well as the value of the units sold. Reported sales under the TRR represent manufacturer shipments of tobacco products to wholesalers or retailers, with the province of the wholesaler/retailer identified for each tobacco product. Returns to companies from wholesalers and retailers are also reported as negative values. All data are subject to revision in the future based on resubmissions by companies and/or audits by Health Canada.

Manufacturers are also required to provide sales of products to duty free stores and data on tobacco products for export, but these data are not included as part of this analysis and the Federal Government policy was to exempt products for export from domestic flavour restrictions. The data used for this analysis begin on 1 January 2004 and end on 31 December 2015. The regulations came into force on 8 October 2009, and consequently the first quarter of 2010 is identified as the intervention point.

\section{Variables}

Sales data were merged into a master database in Stata V.14. For each quarter, net unit sales of cigars in total and by explicitly/ non-explicitly flavoured were calculated. Health Canada's classification of explicitly flavoured products was used. It is important to note that we only classify the products here by flavour descriptors not the presence of flavourings or aroma. Products prior to the flavour regulations may have included flavourings, but if the brand name did not contain an identifiable flavour descriptor it would not be classified here as flavoured; consequently, the term flavoured here refers to the descriptor not the additives.

Similar to Delnevo et al's ${ }^{9}$ classification methodology, explicit flavours were categorised into one of the following groups: no flavoured descriptor, fruit (eg, white grape, strawberry), alcohol (wine, rum, whiskey, port), mint/menthol and cocktail (eg, pina colada). Products labelled as sweet or spicy (sweet, maple syrup, cinnamon) were categorised separately. Cigars with colour descriptors such as red or blue were categorised as not having flavour descriptors.

\section{Statistical analysis}

A segmented regression for interrupted time series was done using the ITSA program in Stata V.14. ${ }^{11}$ The following was the basic model:

$$
Y_{t}=\beta_{0}+\beta_{1} T_{t}+\beta_{2} X_{t}+\beta_{3} X_{t} T_{t}+\varepsilon_{t}
$$

where $t$ is the time since January $2004, X_{t}$ is an indicator variable representing the intervention, $\beta_{0}$ is the starting level of cigar sales, $\beta_{1} T_{t}$ is the slope or trajectory of sales until the introduction of regulations, $\beta_{2} X_{t}$ is the change in the level of sales that occurs in the quarter immediately following the regulations (compared with the counterfactual without regulations), and $\beta_{3} X_{t} T_{t}$ is the difference between the preintervention and postintervention slopes or trajectories. Thus we look at the magnitude and CIs of $\beta_{2}$ to estimate the immediate association of the regulation and $\beta_{3}$ for the treatment effect over time. ${ }^{11}$ Dummy variables representing each seasonal quarter were added to control for seasonality. Newey-West robust SEs were used to control for autocorrelation. The procedure of Baum and Schaffer test as implemented in the Stata procedure actest was used to assess autocorrelation.

Separate regressions were conducted for sales of all cigars, sales of cigars with no flavour descriptors and sales of cigars with flavour descriptors.

A series of sensitivity analyses were conducted to test for validity of assumptions. First, the date of the intervention was set to 1 year prior and 1 year after the intervention (ie, first quarter of 2009 and first quarter of 2011, respectively, instead of the intervention date of first quarter of 2010). Second, a multiple comparison model was developed limiting the data set to Ontario and British Columbia data. Interaction terms were created between a provincial dummy indicator and each of the parameters in the model. The magnitude of the interaction represents the differences in level and slope between the provinces.

\section{RESULTS}

Sales of cigars increased substantially over the period from 304 million cigars across 2004 rising to 650 million units in 
Table 1 Interrupted time series regression results for the 2009 flavour ban in Canada

\begin{tabular}{|c|c|c|c|}
\hline & $\begin{array}{l}\text { All cigars, } B(95 \% C l) \\
n=48\end{array}$ & $\begin{array}{l}\text { No flavour descriptor, } B(95 \% \mathrm{Cl}) \\
\mathrm{n}=48\end{array}$ & $\begin{array}{l}\text { Flavour descriptor, } \mathrm{B}(95 \% \mathrm{Cl}) \\
\mathrm{n}=48\end{array}$ \\
\hline Initial level (2004 first quarter) $\beta_{0}$ & $45.7(37.3 \text { to } 54.2)^{* *}$ & $44.9(39.9 \text { to } 50.0)^{* *}$ & $0.8(-9.3$ to 11.0$)$ \\
\hline Preintervention slope $\beta_{1} T_{\mathrm{t}}$ & $4.9(4.3 \text { to } 5.5)^{* *}$ & $-0.8(-1.4 \text { to }-0.3)^{*}$ & $5.7(5.0 \text { to } 6.5)^{* *}$ \\
\hline $\begin{array}{l}\text { Postintervention level } \\
\text { Change ( } 2010 \text { first quarter) } \beta_{2} X_{t}\end{array}$ & $-49.6(-73.5 \text { to }-25.8)^{* *}$ & $9.6(-1.3$ to 20.5$)$ & $-59.2(-86.0 \text { to }-32.4)^{* *}$ \\
\hline $\begin{array}{l}\text { Postintervention } \\
\text { Change in trend } \beta_{3} X_{t} T_{t}\end{array}$ & $-6.9(-8.1 \text { to }-5.7)^{* *}$ & $0.8(0.2 \text { to } 1.3)^{*}$ & $-7.7(-8.9 \text { to }-6.5)^{* *}$ \\
\hline
\end{tabular}

Outcome wholesale volume sales of cigars (millions of units) per quarter, total, and by brands with or without flavour descriptors. $\mathrm{n}=48$.

Flavour descriptor as identified by brand descriptor.

Enactment date of regulation: 8 October 2009.

All analyses control for seasonality by quarter.

${ }^{*} \mathrm{P}<0.05,{ }^{*} \mathrm{p}<0.001$.

2009 , with over 205 million units in the third quarter of 2009 alone. Thereafter a sharp decline was observed among the total sales of cigars (see table 1 and figure 1 ). The regression analysis suggested that the intervention date was associated with level change, or a decrease in sales, of cigars by 49.6 million units $(95 \% \mathrm{CI}-73.5$ to -25.8$)$. This was also associated with a decrease in slope $(6.9$ million units per quarter $(95 \% \mathrm{CI}$ -8.1 to -5.7$)$ ).

Similarly, flavoured cigars demonstrated rapid increase in sales in the preintervention period with a level change associated with the intervention date of 59 million units $(95 \% \mathrm{CI}$ -86.0 to -32.4 ). There was incomplete substitution to cigars without a flavour descriptor with a 9.6 million unit increase in cigar sales (95\% CI -1.3 to 20.5$)$ (see table 1 and figure 2).

An analysis was conducted using data from only Ontario and British Columbia (see online supplementary table 1 and figure 2). As Ontario is the largest province that introduced comprehensive tobacco control legislation in January 2010, it could have been the case that changes in Ontario were driving the overall effect. As British Columbia is smaller than Ontario, it would be expected that the baseline intercept would be different between the two provinces $(23.9$ million units per quarter (95\% CI 20.0 to 27.8$)$ ), but the minimal difference in the preintervention slope $(0.2$ million unit increase per quarter $(95 \% \mathrm{CI}$ -0.1 to 0.4$)$ ) suggests that would be an effective control group. However, while large postintervention changes were seen, there

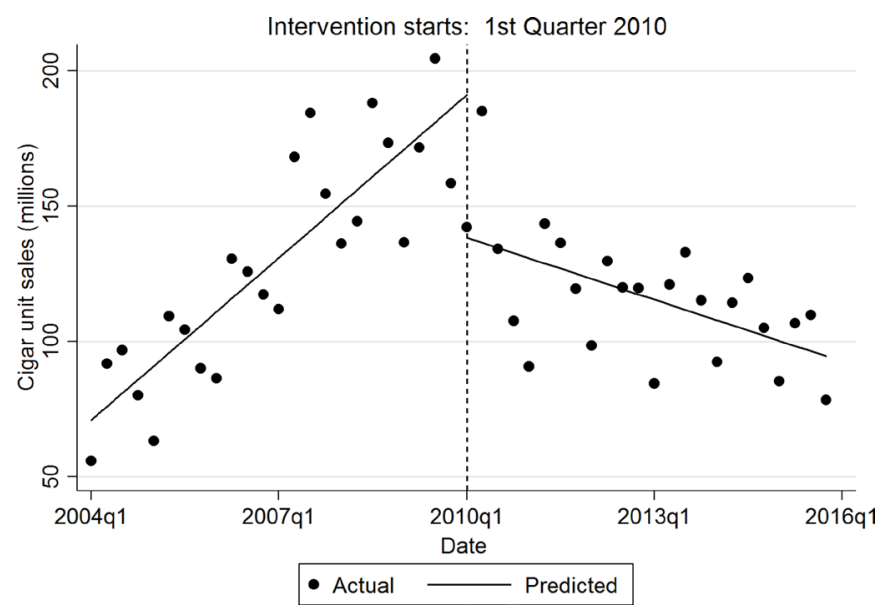

Figure 1 Cigar unit wholesale volume sales in millions wholesale per quarter in Canada, 2004-2015, with model-predicted sales. Flavour descriptor as identified by brand descriptor. Enactment date of regulation: 8 October 2009. $n=48$. were minimal differences between the provinces. This adds evidence to suggest that the changes should be attributed to the Federal regulations rather than any provincial initiatives.

Sensitivity analyses suggest that seasonality was apparent in the data (see online supplementary data for estimates of seasonal control: online supplementary table 1, online supplementary table 3 and online supplementary figure 1) and that controlling for seasonality reduced the magnitude of the change in level modestly. Tests for autocorrelation found residual autocorrelation at the second lag, suggesting a final model including specification for two lag models (all models presented use the specification) was appropriate. A sensitivity analysis, changing the intervention date, suggests that the estimate of the level change is sensitive to earlier dates, and insensitive to later ones, while the trend was insensitive for both earlier and later dates.

Sales of fruit-flavoured and sweet-flavoured cigars declined after the 2009 flavour intervention (figure 3). Sales of alcohol (not including cocktail), menthol and coffee were very low until post-2008 and increased in the case of menthol or stabilised in the case of alcohol. Sales of brands with no flavour descriptors but colour descriptors increased after the enactment of the flavour regulations.

\section{DISCUSSION}

This analysis demonstrates the feasibility and potential impact of regulations banning flavourings in cigar products. The 2009 flavour regulations significantly reduced unit sales of cigars and reversed the trend towards increasing flavoured sales; however, they may have contributed to a rise in menthol and other types of exempted flavoured cigars. Analysis comparing sales of cigars in the provinces of Ontario and British Columbia continued to find an overall relationship between the regulations, and the lack of differences between the provinces strengthens the interpretation that the Federal regulations were responsible for the changes in sales.

Advocates had noted that with the 2009 regulations manufacturers marginally increased the weight of the cigars to continue using flavour and the Federal Government, following a number of other provinces that introduced further legislation in 2015 in an attempt to close this 'loophole'. Despite the presence of the loophole, the flavour regulations were associated with a decline in sales of 49 million cigars. However, sales of cigars in Canada in 2015 (374 millions units) were higher than the start of the study in 2004 (304 million units).

These results suggest that careful consideration of the design of flavour regulations is required in order to maximise the impact of flavour regulations. Substitution between flavoured and 

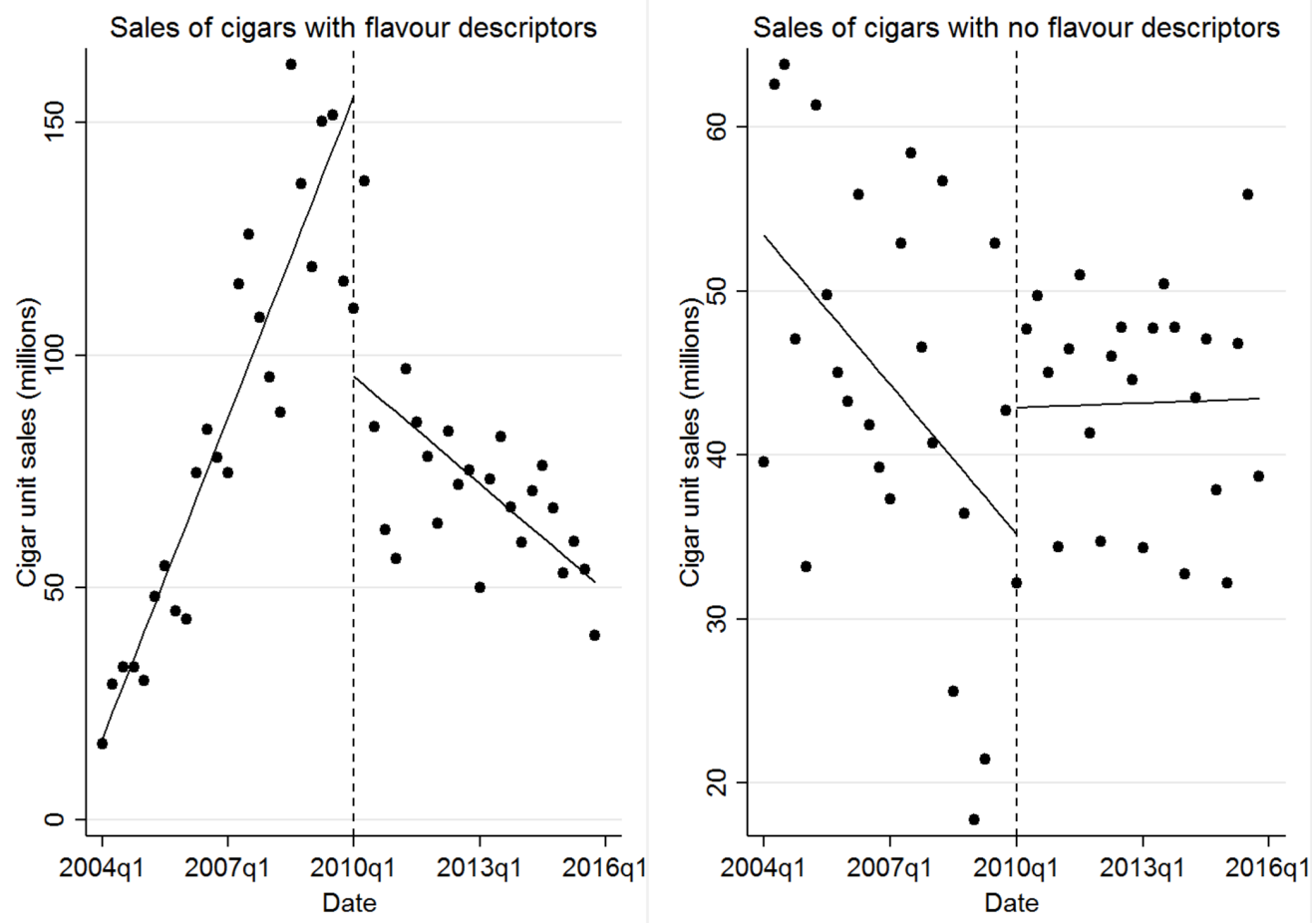

Figure 2 Cigar unit wholesale volume sales by flavour descriptors wholesale per quarter in Canada, 2004-2015, with model-predicted sales. Flavour descriptor as identified by brand descriptor. Enactment date of regulation: 8 October 2009. n=48. • Actual; — predicted linear fit.
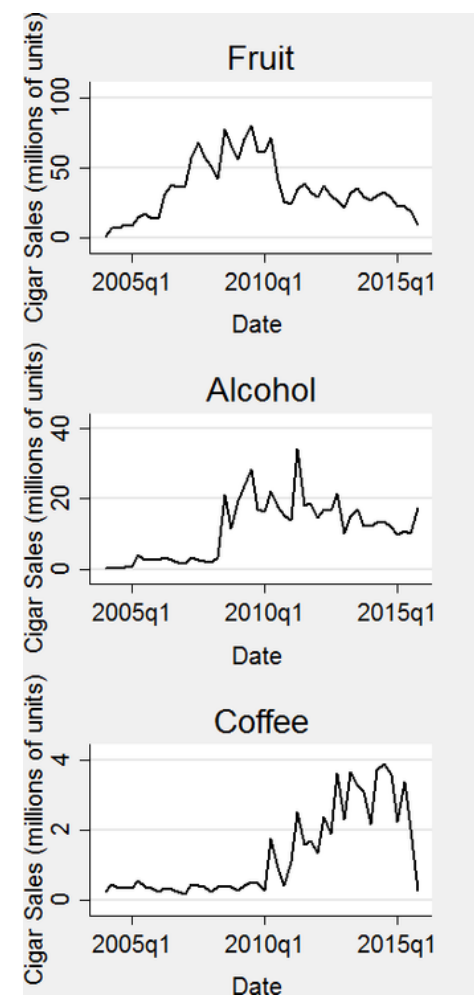
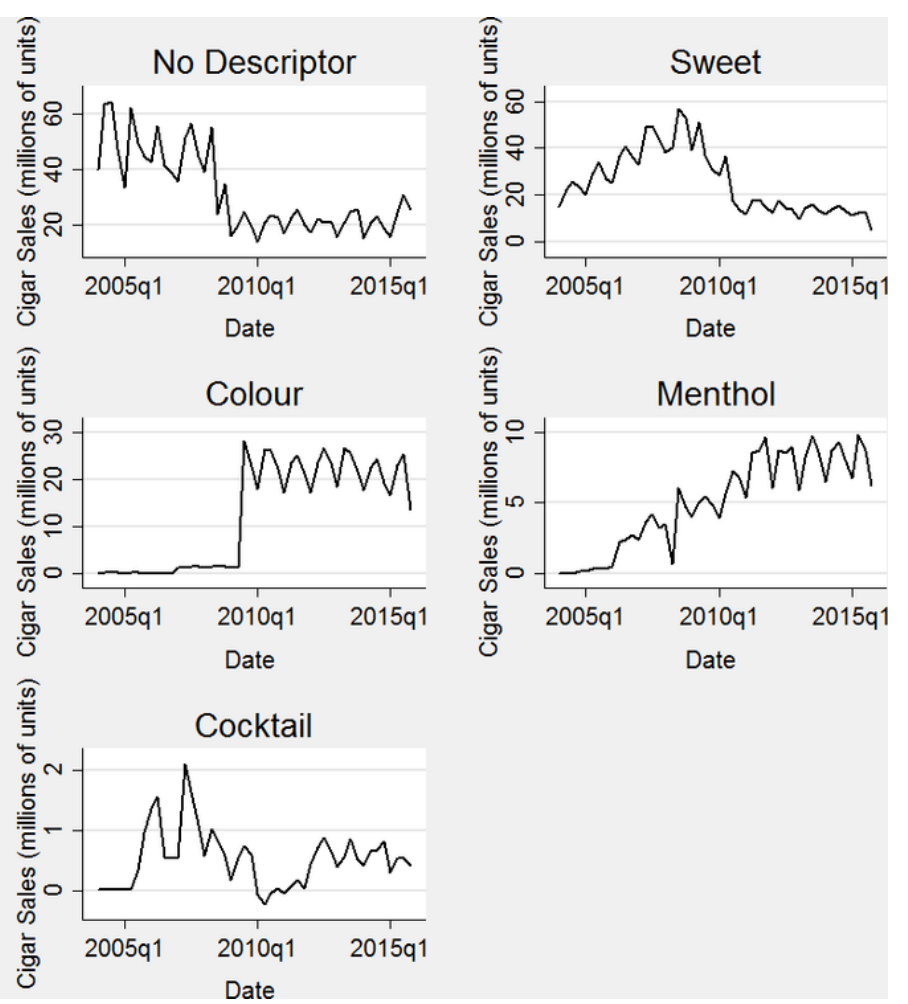

Figure 3 Cigar unit net quarterly wholesale volume sales of cigars in Canada by flavour descriptor, 2004-2015. Alcohol descriptors include basic alcohol flavours (rum, wine, whisky, port); menthol flavours include mint; coffee includes cream descriptors; cocktail includes mixed alcohol drinks such as pina colada; colour descriptors do not have a flavour but include red, white, black, blue and so on; sweet flavours include descriptors such as sweet and maple syrup —other spice flavours are grouped here as well; fruit flavours include watermelon, cherry, berry and other described fruits. Products are classified by descriptors only and may contain flavourants. Enactment of regulation: 8 October 2009. $n=48$. 
unflavoured cigars between types of flavour with these product categories was observed in Canada. More complete bans on flavourings could improve the impact of these restrictions and theoretically the ability of these measures to achieve their objective of protecting youth from inducements to tobacco use. As demonstrated in New York City, ${ }^{45}$ regulations were successful in removing from legal sales the specific products banned for sales, but these regulations can vary in the types of product substitution that may occur. In New York relabelled products were also found with ambiguous descriptors but the same ingredients. ${ }^{12}$ After 2009 in Canada, some flavoured cigar brands raised their weight and continued to market the products as flavoured. Other flavoured brands raised their weight but relabelled to colour descriptorsperhaps to avoid using flavour descriptors that would have given the impression of having evaded the spirit of the law. The Federal regulations on flavour restrictions were based on a schedule of prohibited additives, rather than 'characterising flavours', and did not regulate flavour descriptors; however, the Ontario regulations did regulate the description as well. Consequently, those products with flavour descriptors likely correctly identified products with flavour additives; however, it is possible that there would be flavour additives in products without flavour descriptors. Additionally, this study did not necessarily classified brands with flavours as part of the brand as having a flavour descriptor. For example, Wild Honey Original Cigar would have been labelled as having no flavour descriptor, while Wild Honey Cherry Cigar would have been classified as fruit-flavoured. This interpretation was consistent with the interpretations of the regulations by the Federal and provincial governments.

While some previous studies ${ }^{713-15}$ have used changes in the dollar value of sales to evaluate the impact of flavour regulations, the use of dollar value of sales to estimate total units sold may be misleading if tobacco companies are using price (specifically lowering the prices on certain products) to soften the impact of flavour regulations on sales. Consequently use of dollar sales may lead to underestimates of the impact in some jurisdictions. This analysis uses changes in the sale of the number of units, avoiding having to make additional assumptions around inflation. Future research may explore changes in the price of flavoured and unflavoured products after the enactment to moderate the impact of flavour regulations.

This analysis also uses wholesale rather than retail sales. Data presented are derived from tobacco industry sales reports submitted to Health Canada. Data represent reported shipments by tobacco manufacturers and importers to wholesalers and retailers in the province of record. For smaller provinces (Prince Edward Island and the territories), data may not accurately represent total consumption, as wholesalers and retailers in those province and territories may receive product from wholesalers in large provinces.

Interpretation of interrupted time series analysis without a control group may be confounded by other interventions at the same time. The internal control examining two provinces with different sets of other interventions suggests that other factors would not be sufficient to explain the change, but the possibility cannot be ruled out.

Analysis of tobacco wholesale data in Canada suggests that flavoured tobacco regulations may have had a substantial impact on sales of tobacco products. This study used interrupted time series analysis to show changes in sales of cigars after the enactment of flavour restrictions by the Federal Government in 2009. Other jurisdictions considering implementation of regulations on flavoured tobacco should consider potential substitution effects.
What this paper adds

- Many countries are considering flavour restrictions on tobacco products, but there are few evaluations of their effectiveness.

- This article uses an interrupted time series analysis to assess changes in cigar sales associated with flavour regulations in the Canadian provinces of Ontario and British Columbia in 2009.

- The initial restriction on flavours in smaller cigar products had a large association with changes in sales.

- Enactment of the regulations was also associated with changes in the type of descriptors.

Contributors All authors contributed to the design of the study. RN and GT were responsible for data collection and cleaning. MOC conducted the analysis. All authors contributed to writing and editing for substantive intellectual content.

Funding The authors have not declared a specific grant for this research from any funding agency in the public, commercial or not-for-profit sectors.

Competing interests Some of the authors work for Health Canada, which is responsible for implementing the policy evaluated in this paper.

Patient consent Not required.

Provenance and peer review Not commissioned; externally peer reviewed.

Open access This is an open access article distributed in accordance with the Creative Commons Attribution Non Commercial (CC BY-NC 4.0) license, which permits others to distribute, remix, adapt, build upon this work non-commercially, and license their derivative works on different terms, provided the original work is properly cited, appropriate credit is given, any changes made indicated, and the use is non-commercial. See: http://creativecommons.org/licenses/by-nc/4.0/.

\section{REFERENCES}

1 Huang LL, Baker HM, Meernik C, et al. Impact of non-menthol flavours in tobacco products on perceptions and use among youth, young adults and adults: a systematic review. Tob Control 2017;26:709-19.

2 Carpenter CM, Wayne GF, Pauly JL, et al. New cigarette brands with flavors that appeal to youth: tobacco marketing strategies. Health Aff 2005;24:1601-10.

3 Farley SM, Johns M. New York City flavoured tobacco product sales ban evaluation. Tob Control 2017;26:78-84.

4 Rogers T, Brown EM, Mccrae TM, et al. Compliance with a sales policy on flavored non-cigarette tobacco products. Tob Regul Sci 2017;3:84-93.

5 Ontario Tobacco Research Unit. Prohibitions/restrictions on flavoured tobacco products: monitoring update OTRU: Toronto, Ontario. 2013. http://otru.org/prohibit ionsrestrictions-flavoured-tobacco-products-2013-monitoring-update/

6 Minaker LM, Ahmed R, Hammond D, et al. Flavored tobacco use among Canadian students in grades 9 through 12: prevalence and patterns from the 2010-2011 youth smoking survey. Prev Chronic Dis 2014;11:140094.

7 Corey CG, Ambrose BK, Apelberg BJ, et al. Flavored tobacco product use among middle and high school stud ents-United States, 2014. MMWR Morb Mortal Wkly Rep 2015;64:1066-70.

8 Villanti AC, Richardson A, Vallone DM, et al. Flavored tobacco product use among U.S. young adults. Am J Prev Med 2013;44:388-91.

9 Delnevo CD, Wackowski OA, Giovenco DP, et al. Examining market trends in the United States smokeless tobacco use: 2005-2011. Tob Control 2014;23:107-12.

10 Bernal JL, Cummins S, Gasparrini A. Interrupted time series regression for the evaluation of public health interventions: a tutorial. Int J Epidemiol 2017;46:dyw098.

11 Linden A. Conducting interrupted time-series analysis for single-and multiple-group comparisons. Stata J 2015;15:480-500.

12 Farley SM, Schroth KR, Grimshaw V, et al. Flavour chemicals in a sample of noncigarette tobacco products without explicit flavour names sold in New York City in 2015. Tob Control 2018;27:170-6.

13 Kowitt SD, Meernik C, Baker HM, et al. Perceptions and experiences with flavored non-menthol tobacco products: a systematic review of qualitative studies. Int J Environ Res Public Health 2017:14:338.

14 Delnevo CD, Giovenco DP, Miller Lo EJ. Changes in the mass-merchandise cigar market since the tobacco control act. Tob Regul Sci 2017:3(2 Suppl 1):8-16.

15 Delnevo CD, Hrywna M. Clove cigar sales following the US flavoured cigarette ban. Tob Control 2015;24:e246-e250. 